\title{
Características de crescimento e desenvolvimento do milho crioulo com diferentes adubações orgânicas
}

\author{
Fátima de Souza Gomes ${ }^{1}$, Rafael Alves dos Santos², Diogo Barreto Magalhães ${ }^{3}$, Felizarda Viana Bebé ${ }^{4}$
}

\begin{abstract}
Resumo
A sociedade torna-se cada vez mais consciente em relação às externalidades apresentadas pela agricultura convencional, assim, a demanda por sistemas que degradem menos o meio ambiente é crescente. Neste contexto, objetivou-se caracterizar o desempenho agronômico do milho em solo adubado com diferentes adubações orgânicas. O delineamento experimental foi em blocos aleatorizados 5 tratamentos e 15 repetições, totalizando 75 unidades experimentais. Os tratamentos foram: testemunha (sem adubo); esterco bovino ( $40 \mathrm{t} \mathrm{ha}^{-1}$ ); esterco aviário ( $\left.5 \mathrm{t} \mathrm{ha}^{-1}\right)$; esterco caprino (65 tha ${ }^{-1}$ ) e misto (bovino+aviário+caprino) (36 t ha $\left.{ }^{-1}\right)$. Aos 14, 21, 28 e 35 dias após o plantio (DAP) foi mensurada a altura da planta, número de folhas e diâmetro do colmo; a altura da primeira espiga no colmo aos 80 DAP. Os resultados demonstram que para os caracteres avaliados, os menores valores foram observados no tratamento com esterco bovino. A adubação mista proporcionou aumento no número de folhas. O esterco de caprinos promoveu maior diâmetro do colmo e número de espiga/planta. O peso da espiga/planta foi incrementado com o uso do esterco caprino e do esterco misto.
\end{abstract}

Palavras-chave: Estercos. Sustentabilidade. Zea mays L.

\section{Characteristics of growth and development of landrace maize with different organic fertilizers}

\begin{abstract}
Society becomes increasingly aware of the externalities presented by conventional agriculture, so the demand for less environmentally degrading systems is increasing. In this context, the objective was to characterize the agronomic performance of corn in soil fertilized with different organic fertilizers. The experimental design was in randomized blocks 5 treatments and 15 repetitions, totaling 75 experimental units. The treatments were: control (without fertilizer); cattle manure $\left(40 \mathrm{t} \mathrm{ha}^{-1}\right)$; poultry manure $\left(5 \mathrm{t} \mathrm{ha}^{-1}\right)$; goat $\left(65 \mathrm{t} \mathrm{ha}^{-1}\right)$ and mixed manure (cattle + poultry + goat) $\left(36 \mathrm{t} \mathrm{ha}^{-1}\right)$. At 14, 21, 28 and 35 days after planting (DAP), plant height, leaf number and stem diameter were measured; the height of the first ear in the stem at $80 \mathrm{dbh}$. The results demonstrate that for the evaluated characters, the lowest values were observed in the treatment with cattle manure. Mixed fertilization increased the number of leaves. The goat manure promoted larger stem diameter and number of ear / plant. The weight of the ear / plant was increased with the use of goat and mixed manure.
\end{abstract}

Keywords: Dung. sustainability. Zea mays L.

\footnotetext{
${ }^{1}$ Instituto Federal de Educação, Ciência e Tecnologia Baiano, Campus de Guanambi. Guanambi, Ba. Brasil http://orcid.org/0000-0003-2963-8342

${ }^{2}$ Instituto Federal de Educação, Ciência e Tecnologia Baiano, Campus de Guanambi. Guanambi, Ba. Brasil http://orcid.org/0000-0002-3509-169X

${ }^{3}$ Instituto Federal de Educação, Ciência e Tecnologia Baiano, Campus de Guanambi. Guanambi, Ba. Brasil http://orcid.org/0000-0002-0800-9136

${ }^{4}$ Instituto Federal de Educação, Ciência e Tecnologia Baiano, Campus de Guanambi. Guanambi, Ba. Brasil http://orcid.org/0000-0001-5459-6303

*Autora para correspondência: souzafa86@gmail.com
}

Recebido para publicação em 01 de novembro de 2019. Aceito para publicação em 19 de novembro de 2019. e-ISSN: 2447-6218 / ISSN: 2447-6218 / (C) 2009, Universidade Federal de Minas Gerais, Todos os direitos reservados. 


\section{Introdução}

O milho (Zea mays L.), pertence à família Poaceae, é uma espécie originária da América do Norte, um dos cereais mais cultivados no mundo, tendo um papel significativo na economia por apresentar alto valor comercial na produção de grãos, possuindo alta produtividade devida sua habilidade em adaptar-se a condições ambientais adversas (Silveira et al., 2015).

O Brasil é o terceiro maior produtor mundial de milho, ficando somente atrás dos Estados Unidos e da China. De acordo a Companhia Nacional de Abastecimento (2016), na safra 2015/16 o Brasil plantou 16 milhões de hectares, com produção total de 82,3 milhões de toneladas, e o Rio Grande do Sul teve uma participação de $7 \%$ na produção total do cereal, com uma produção média de 6,5 tha.

Geralmente as cultivares são selecionadas para responder a adubação solúvel, resistência a pragas e altas produtividades de grãos (Eicholz et al., 2016). Nos últimos 30 anos, as tradicionais variedades de milho ou variedades locais, de polinização aberta, foram substituídos por cultivares híbridas, em especial híbridos simples e triplos com maior potencial produtivo, porém mais exigentes em tecnologia de produção (adubação, irrigação e defensivos) para expressar seu potencial produtivo (Emygdio et al., 2008).

A alta produtividade do milho, independente da região de cultivo, é consequência do emprego de várias tecnologias de produção como: correção e fertilização adequada do solo, plantio direto, manejo integrado de plantas invasoras, doenças e pragas, assim como da adoção de sementes de qualidade genética superior, como as geneticamente modificadas (Eicholz et al., 2016).

Em condições que se empregam baixas tecnologias de cultivo, as variedades comerciais podem apresentar desempenho próximo ou mesmo inferior às variedades cultivadas pelo agricultor (Carpentieri et al., 2010). Além da diversidade genética que representam, outro aspecto fundamental referente às variedades crioulas é que elas não são estáticas, ao contrário, estão em permanente processo evolutivo e de adaptação às condições ambientais e sistemas de cultivo (Cunha, 2013).

Para Santos et al.; (2017), sementes crioulas são variedades produzidas por agricultores familiares, quilombolas, indígenas ou assentados com características reconhecidas pelas comunidades que as cultivam. Para isso, é importante também que se comece pelo resgate da tradição de cultivar a semente crioula e preservar as que existem (Santos et al., 2017).

As sementes crioulas podem ser definidas também como aquelas que durante um longo período de tempo, foram conservadas, cultivadas e selecionadas por agricultores em suas regiões, não sofrendo modificações por meio de melhoramento genético artificial, adaptadas às biointerações presentes nos agroecossistemas, contribuindo com a sustentabilidade e diversidade, além de serem mais rústicas e resistentes (Macêdo et al., 2016).

A fim de minimizar os custos de produção para maior competitividade e melhoria da qualidade do produto processado, a determinação e o conhecimento do comportamento das propriedades das sementes de girassol são os principais fatores a contribuírem para o adequado desenvolvimento dos processos e simulações, que visem aperfeiçoar o sistema produtivo dessa cultura, o que torna o conhecimento das propriedades físicas dos grãos relevante (Milane et al., 2015).

No Nordeste o milho contribui de forma significante na alimentação animal, onde entra como componente básico principalmente na forma de silagem, sendo conservado no período chuvoso e disponibilizado aos animais na estiagem.

Conforme Ferreira et al., (2010), é necessário utilizar técnicas de recuperação e fertilização orgânica dos solos para viabilizar o retorno das condições de equilíbrio ecológico e reduzir utilização de adubos minerais no sistema produtivo. $\mathrm{O}$ aproveitamento de adubo orgânico de origem animal no cultivo agrícola tem sido uma prática utilizada na busca de alternativas para substituir os adubos minerais.

Neste contexto, objetivou-se avaliar o crescimento e desenvolvimento do milho com utilização de diferentes fontes de adubação orgânica.

\section{Material e métodos}

A área experimental está localizada no Instituto Federal de Educação, Ciência e Tecnologia Baiano - Campus Guanambi, no município de Guanambi- BA, Micro Região da Serra Geral, com latitude de $14^{\circ} 17^{\prime} 21.73$ " sul, longitude de 4241'36.54" oeste de Greenwich, altitude de 551 metros, em Latossolo Vermelho - Amarelo distrófico, típico A fraco, de textura média, fase caatinga hipoxerófila, relevo plano a suave ondulado.

O estudo foi conduzido no período de outubro de 2017 a março de 2018. As temperaturas máximas, médias e mínimas, registradas no período experimental constam na figura 1 . Verifica-se temperaturas mínimas por volta de $22^{\circ} \mathrm{C}$ e temperaturas máximas próximas de $40^{\circ} \mathrm{C}$. Observam-se também chuvas nos meses de novembro, dezembro, fevereiro e março. 
Características de crescimento e desenvolvimento do milho crioulo com diferentes adubações orgânica

Figura 1 - Temperatura máxima, média e mínima durante o período experimental. Estação automática. Guanambi, BA, 2017 - 2018

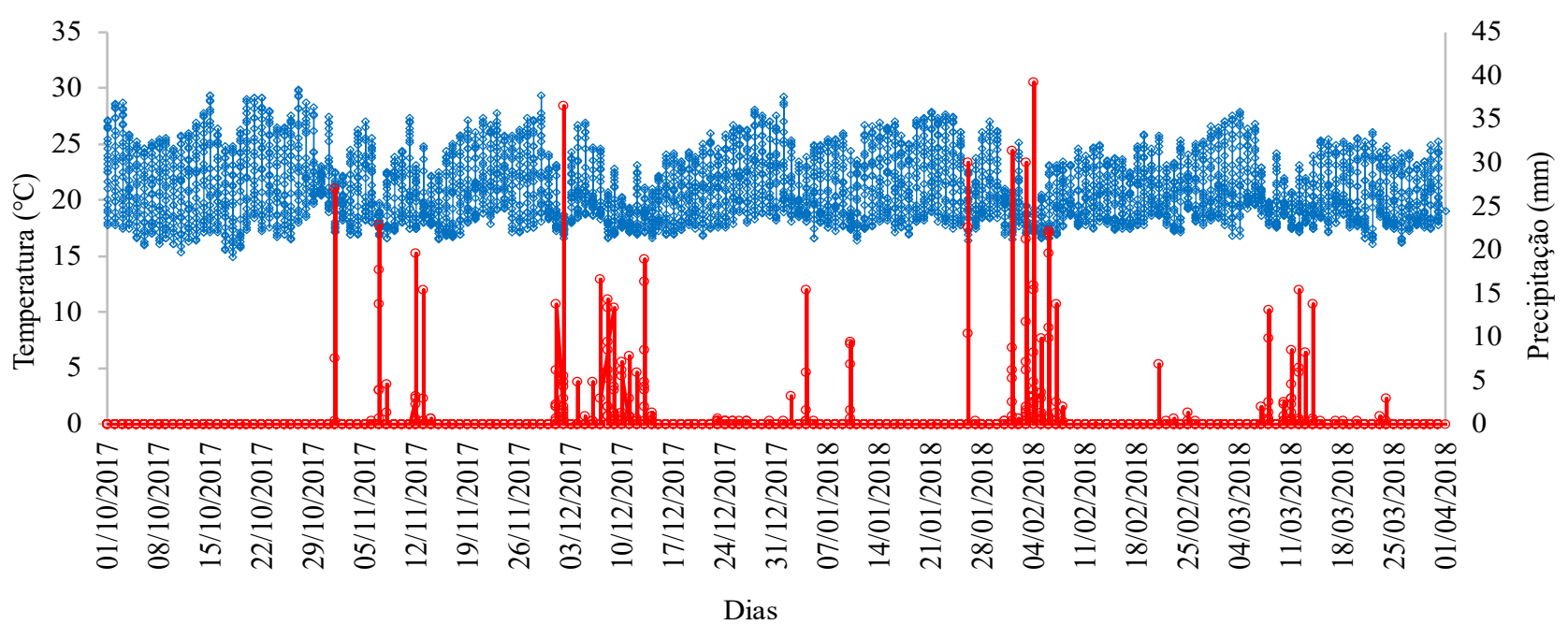

Antes da instalação do experimento foi coletado solo, proveniente de barranco para o preenchimento dos vasos. Coletaram-se também, amostras simples, com trado holandês, para formar uma amostra composta, de maneira aleatória e representativa, nas camadas de $0,2-0,4 \mathrm{~m}$ de profundidade e posteriormente foi seca ao ar, destorroada e peneirada com malha de $2 \mathrm{~mm}$, para caracterização química. A tabela 1 apresenta as características química e física do solo determinadas no Laboratório de solos da Universidade Estadual do Sudoeste Baiano (UESB), conforme a metodologia da Embrapa (2017).

Tabela 1 - Caracterização química do solo utilizado no cultivo do milho crioulo. Guanambi, BA, 2017- 2018

\begin{tabular}{cccccccccccc}
\hline Profundidade & $\mathbf{p H}$ & $\mathbf{P}$ & $\mathrm{K}+$ & $\mathbf{C a} 2+$ & $\mathbf{M g} 2+$ & $\mathrm{Al3}+$ & $\mathbf{H}+$ & S.B. & $\mathbf{t}$ & $\mathbf{T}$ & $\mathbf{V}$ \\
\hline \multicolumn{1}{c}{$\mathrm{mg} \mathrm{dm}-3$} & & & & & & cmolc/dm3 & & \\
\hline $0-0,2 \mathrm{~m}$ & 7,3 & 22 & 0,56 & 5,8 & 1,7 & 0,0 & 1,2 & 8,1 & 8,1 & 9,3 & 87 \\
\hline
\end{tabular}

pH: Potencial Hidrogeniônico; P: Fósforo; $\mathrm{K}^{+}$: Potássio; $\mathrm{Ca}^{2+}$ : Cálcio; $\mathrm{Mg}^{2+}$ : Magnésio; $\mathrm{Al}^{3+}$ : Alumínio; S.B.: Soma de bases; $\mathrm{H}^{+}+\mathrm{Al}^{3+}$ : Hidrogênio + Alumínio.

O delineamento experimental foi em blocos aleatorizados com 5 tratamentos e 15 repetições, totalizando 75 unidades experimentais. Cada unidade experimental foi representada por uma planta cultivada em vaso de polietileno com capacidade de $10 \mathrm{~kg}$. Sendo os tratamentos: testemunha (sem adubo); esterco bovino ( $\left.40 \mathrm{t} \mathrm{ha}^{-1}\right)$; esterco aviário ( $\left.5 \mathrm{t} \mathrm{ha}^{-1}\right)$; esterco caprino $\left(65 \mathrm{t} \mathrm{ha}^{-1}\right)$ e o misto (bovino+aviário+caprino) - $36 \mathrm{t} \mathrm{ha}^{-1}$.

O esterco utilizado foi proveniente dos setores de bovinocultura, caprinocultura e aviário do IF Baiano - Campus Guanambi, e as quantidades de esterco adicionadas foram equivalentes às doses dos tratamentos, que foram incorporadas no momento do plantio ao volume de solo que preencheu cada vaso.

As doses em cada tratamento foram definidas com base nos parâmetros de acordo com a exigência nutricional de $\mathrm{N}$ para a cultura do milho, segundo a recomendação da Comissão Estadual de Fertilidade do Solo (BA).
A semeadura foi realizada em novembro de 2017, a uma profundidade de $2 \mathrm{~cm}$, semeando sementes de milho crioulo destinado ao consumo in natura disponibilizada por agricultor local advindos do seu banco de sementes. A semente de milho crioulo é originada do processo de resgate e multiplicação de sementes de milho crioulo, realizado por produtores que praticam a agricultura familiar no sudoeste da Bahia, o ciclo dura em média de 3 a 4 meses, e são sementes resistentes, adaptadas.

A emergência das plântulas de milho ocorreu no dia 16 de novembro de 2017. O desbaste foi realizado sete dias após o plantio, deixando uma planta por vaso, preferencialmente as que apresentavam três a quatro folhas totalmente expandidas (planta mais vigorosa). Caracterizar melhor a variedade de milho utilizada, de acordo com informações do agricultor ou outras fontes.

A colheita foi realizada manualmente aos 90 dias após a semeadura, quando os grãos apresentaram o endosperma amarelado e leitoso, com espigas empalhadas. 
Gomes, F. de S. et al.

A irrigação foi realizada diariamente aplicando-se a mesma quantidade de água para todas as unidades experimentais, mantendo-se a umidade próxima à capacidade de campo, para isso utilizava se um único recipiente de volume conhecido, e com isso era determi- nado a quantidade de água a ser disponibilizada em cada vaso diariamente. Para a análise da água, foi coletado amostras em pontos distintos na rede do experimento (Tabela 2). A água utilizada foi classificada como C2S1 conforme Barroso et al., (2011).

Tabela 2 - Determinação dos atributos químicos da água utilizada. Guanambi, 2017 - 2018

\begin{tabular}{|c|c|c|c|}
\hline Parâmetro & Unidade & Valor medido & Padrão $^{(*)}$ \\
\hline $\mathrm{pH}$ & - & 6,6 & $6,5-8,4$ \\
\hline C.E. & $\mathrm{dS} \mathrm{m}^{-1}$ & 1,75 & $<0,7$ \\
\hline Alcalinidade & $\mathrm{mg} \mathrm{L}^{-1}$ & 206 & $<91,6$ \\
\hline Cloretos & $\mathrm{mg} \mathrm{L}^{-1}$ & 0,11 & $<106,3$ \\
\hline Dureza & $\mathrm{mg} \mathrm{L}^{-1}$ & 295,9 & $<321,9$ \\
\hline Sódio & $\mathrm{mg} \mathrm{L}^{-1}$ & 51,8 & $<68,9$ \\
\hline RAS & - & 6,0 & $<10$ \\
\hline
\end{tabular}

pH H $\mathrm{H}_{2} \mathrm{O}$ : potencial Hidrogeniônico; CE: Condutividade Elétrica; CL: Cloro ; Dureza (Ca+Mg); Na+: Sódio; RAS: Reação de Adsorção de Sódio.

As variáveis de crescimento analisadas foram: altura da planta, número de folhas, diâmetro do colmo, mensuradas aos 14, 21, 28, 35 dias após o plantio (DAP). $\mathrm{E}$ as variáveis de produção: altura de inserção da primeira espiga, número de espigas e peso da espiga/vaso.

Para a determinação da altura da planta, foi mensurada com a utilização de bastão milimetrado, sendo à distância do primeiro nó até a última folha em centímetro - cm (Rodrigues et al., 2012).

Na quantificação do número de folhas por planta foi determinado através da contagem direta, contabilizadas apenas as folhas que se apresentarem limbos totalmente expandidos em unidade (Durães et al., 1995). O diâmetro do caule foi obtido com a utilização de paquímetro, tomando o primeiro internódio da planta em milímetro - mm (Rodrigues et al., 2012).

As variáveis de produção, para a altura da primeira espiga, aos 80 DAP foram tomadas com fita métrica, sendo à distância do primeiro nó até a espiga em centímetro - cm (Araújo; Nass, 2002). O número de espigas foi determinado pela contagem direta das espigas na planta. Já o peso da espiga por vaso, pela pesagem em balança de precisão, no ato da colheita, expressos em kg.

Os dados obtidos das características agronômicas avaliadas foram submetidos a analise de distribuição normal dos dados seguido pela analise de variância. Após realizou-se a comparação das médias efetuada pelo teste de Tukey $(p<0,05)$. Para realização da análise estatística utilizou-se o programa estatístico SISVAR (Ferreira, 2011).

\section{Resultados e discussão}

Os valores médios da característica altura da planta encontram-se detalhados na Tabela 3. Pode-se observar que não houve diferenças significativas aos 14 e 21 dias após o plantio (DAP) para a variável, em função das fontes de adubação orgânica e dias após o plantio de acordo com o teste de Tukey. Porém aos 28 e 35 DAP, observa-se diferença entre os tratamentos com significância de $5 \%(\mathrm{P}<0,05)$. A utilização da fonte de esterco bovino influenciou negativamente na variável mensurada.

Os valores da altura da planta aos 14 e 21 dias após o plantio foram próximos em todas as fontes avaliadas com médias de $12,00 \mathrm{~cm}$ e $24,15 \mathrm{~cm}$, respectivamente. Já aos 28 e 35 DAP, houve um incremento na altura, sendo que o tratamento com esterco bovino apresentou os menores valores médios de $16,25 \mathrm{~cm}$ e $23,25 \mathrm{~cm}$. Plantas de portes mais elevados de milho crioulo foram averiguadas por Coimbra et al. (2010) e Ferreira (2009), com médias de $2,90 \mathrm{~m}$ e $2,70 \mathrm{~m}$, respectivamente.

As variedades crioulas apresentam, geralmente, maior altura de planta, em relação às cultivarem comerciais mais modernas (Ferreira et al., 2009). O motivo dos milhos crioulos estarem entre os mais altos, se explica pelo fato destes não terem sido submetidos à seleção para porte baixo, como ocorre com os híbridos, plantas mais alta apresentam vantagens quando destinadas ao preparo da alimentação animal, para silagem, assim como para uma maior produção de palhada usada na cobertura do solo.

A menor resposta a aplicação de esterco bovino em relação aos demais se deve, possivelmente, em função de uma lenta disponibilidade de nutrientes, pois a mineralização da matéria orgânica presente no esterco 
Características de crescimento e desenvolvimento do milho crioulo com diferentes adubações orgânica

aplicado era bastante incipiente, e se deve também, pelo menor estádio de desenvolvimento das plantas. Segundo Sampaio et al., (2007) corroboram ao afirmar que a uma imobilização de nutrientes do solo no primeiro mês após a incorporação do esterco, com isso não a efeito expressivo no desenvolvimento do milho.

Tabela 3 - Valores médios de altura de plantas milho em função de diferentes fontes de adubação orgânica e épocas de avaliação. Guanambi, BA, 2017 - 2018

\begin{tabular}{|c|c|c|c|c|}
\hline \multirow[t]{2}{*}{ Tratamentos } & \multicolumn{4}{|c|}{ Altura (cm) } \\
\hline & 14DAP & 21 DAP & 28 DAP & 35 DAP \\
\hline Testemunha & $13,50 \mathrm{~A}$ & $24,00 \mathrm{~A}$ & $37,75 \mathrm{~A}$ & $46,00 \mathrm{~A}$ \\
\hline Esterco Caprino & $15,00 \mathrm{~A}$ & $29,25 \mathrm{~A}$ & $49,50 \mathrm{~A}$ & $58,50 \mathrm{~A}$ \\
\hline Esterco Bovino & $8,25 \mathrm{~A}$ & $15,00 \mathrm{~A}$ & $16,25 \mathrm{~B}$ & $23,25 \mathrm{~B}$ \\
\hline Esterco Aviário & $9,50 \mathrm{~A}$ & $23,25 \mathrm{~A}$ & $35,25 \mathrm{~A}$ & $44,50 \mathrm{~A}$ \\
\hline Esterco Misto & $13,75 \mathrm{~A}$ & $29,25 \mathrm{~A}$ & $42,00 \mathrm{~A}$ & $55,75 \mathrm{~A}$ \\
\hline \multirow{2}{*}{$\begin{array}{l}\text { Média } \\
\text { CV (\%) }\end{array}$} & 12,00 & 24,15 & 36,15 & 45,60 \\
\hline & & 23,40 & & \\
\hline
\end{tabular}

Letras maiúsculas diferentes na coluna diferem entre si pelo teste de Tukey a 5\% de probabilidade.

Para as avaliações de diâmetro do colmo (Tabela 4), houve diferenças significativas apenas aos 28 e 35 DAP de acordo com o teste de Tukey. Os resultados de diâmetro observados na fase inicial aos 14 e 21 DAP nos diferentes tratamentos, não houve incremento significativo, apresentando valores próximos de diâmetro entre as mesmas, com médias de $1,79 \mathrm{~mm}$ e $2,86 \mathrm{~mm}$.

Quando avaliado a característica de diâmetro de colmo em função dos dias após o plantio, nota-se que aos 28 e 35 DAP, o tratamento com adubação proveniente do esterco caprino propiciou maior abundância de colmo, com valores médios de diâmetro 5,30 mm e 6,87 mm, respectivamente. Ao tempo que o esterco bovino proporcionou menores valores médio de $2,20 \mathrm{~mm}$ aos 28 DAP e $2,72 \mathrm{~mm}$ aos 35 DAP, caracterizando um menor diâmetro de colmo em relação às demais adubações utilizadas no experimento.

Quanto ao diâmetro do colmo, o aumento deste componente representa um fator importante do ponto de vista fisiológico. Com isso plantas com maiores diâmetros de colmo no desenvolvimento inicial, tendem a se tornar plantas mais vigorosas e produtivas.

Tabela 4 - Valores médios de diâmetro do colmo de plantas de milho em função de diferentes fontes de adubação orgânica e épocas de avaliação. Guanambi, BA, 2017 - 2018

\begin{tabular}{ccccc}
\hline Tratamentos & \multicolumn{4}{c}{ Diâmetro (mm) } \\
\hline 14 DAP & $\mathbf{2 1}$ DAP & 28 DAP & 35 DAP \\
\hline Testemunha & $1,90 \mathrm{~A}$ & $3,00 \mathrm{~A}$ & $3,62 \mathrm{~B}$ & $5,10 \mathrm{C}$ \\
Esterco Caprino & $2,15 \mathrm{~A}$ & $3,22 \mathrm{~A}$ & $5,30 \mathrm{~A}$ & $6,87 \mathrm{~A}$ \\
Esterco Bovino & $1,45 \mathrm{~A}$ & $2,20 \mathrm{~A}$ & $2,20 \mathrm{C}$ & $2,72 \mathrm{D}$ \\
Esterco Aviário & $1,70 \mathrm{~A}$ & $2,80 \mathrm{~A}$ & $4,02 \mathrm{~B}$ & $5,57 \mathrm{BC}$ \\
Esterco Misto & $1,77 \mathrm{~A}$ & $3,10 \mathrm{~A}$ & $4,65 \mathrm{AB}$ & $6,55 \mathrm{AB}$ \\
\hline Média & $\mathbf{1 , 7 9}$ & $\mathbf{2 , 8 6}$ & $\mathbf{3 , 9 6}$ & $\mathbf{5 , 3 6}$ \\
CV (\%) & & $\mathbf{1 6 , 7 9}$ &
\end{tabular}

Letras maiúsculas diferentes na coluna diferem entre si pelo teste de Tukey a 5\% de probabilidade.

Não foram observadas diferenças significativas, entre os tratamentos aos 14 DAP para a variável número de folhas (Tabela 5). Baseado no desenvolvimento inicial (14 DAP), os valores médios variaram de 3,00 a 4,00 com a aplicação dos tratamentos, não apresentando diferença na variável aferida. Porém aos 21,28 e 35 DAP verificou-se diferenças entre os tratamentos. Os nutrientes disponibilizados pelo esterco misto aos 28 dias influenciaram no maior número de folhas com valores médios 8,25 . Ao tempo que, o esterco bovino obteve menores valores 4,75. Aos 35 DAP a cultura se comportou de forma semelhante, com um aumento na média de 6,90 para 7,80 . 
Gomes, F de S. et al.

De acordo com Vieira et al., (2010), a quantidade de folhas por planta influência na produção de biomassa quando aliada à maior altura de planta, estas demonstram um desenvolvimento exuberante das plantas. Outra vantagem em se ter plantas com maior quantidade de folhas é relacionado ao preparo de alimentação animal, quando se destinado a esse fim, por uso de planta inteira para silagem propiciará maior quantidade.
Sabe se também que o potencial produtivo do milho é decorrência do incremento da intensidade fotossintética que está associada aos órgãos que realizam fotossíntese. Portanto, quanto maior número de folhas tem conseguintemente maior capacidade em produzir e armazenar fotoassimilados.

Tabela 5 - Valores médios de número de folhas de plantas milho em função de diferentes fontes de adubação orgânica e épocas de avaliação. Guanambi, BA, 2017 - 2018

\begin{tabular}{|c|c|c|c|c|}
\hline \multirow[t]{2}{*}{ Tratamentos } & \multicolumn{4}{|c|}{ Número de folhas } \\
\hline & 14 DAP & 21 DAP & 28 DAP & 35 DAP \\
\hline Testemunha & $3,75 \mathrm{~A}$ & $5,50 \mathrm{AB}$ & $7,00 \mathrm{AB}$ & $8,00 \mathrm{AB}$ \\
\hline Esterco Caprino & $4,00 \mathrm{~A}$ & $6,75 \mathrm{~A}$ & $8,00 \mathrm{AB}$ & $9,00 \mathrm{AB}$ \\
\hline Esterco Bovino & $3,00 \mathrm{~A}$ & $4,00 \mathrm{~B}$ & $4,75 \mathrm{C}$ & $5,25 \mathrm{C}$ \\
\hline Esterco Aviário & $3,50 \mathrm{~A}$ & $5,25 \mathrm{AB}$ & $6,50 \mathrm{~B}$ & $7,50 \mathrm{~B}$ \\
\hline Esterco Misto & $3,50 \mathrm{~A}$ & $6,25 \mathrm{~A}$ & $8,25 \mathrm{~A}$ & $9,25 \mathrm{~A}$ \\
\hline \multirow{2}{*}{$\begin{array}{l}\text { Média } \\
\text { CV (\%) }\end{array}$} & 3,55 & 5,55 & 6,90 & 7,80 \\
\hline & & 13,23 & & \\
\hline
\end{tabular}

Letras maiúsculas diferentes na coluna diferem entre si pelo teste de Tukey a 5\% de probabilidade.

Quanto à altura da primeira espiga (APE) a testemunha apresentou o mais elevado, com valor médio de $15,87 \mathrm{~cm}$ de inserção da primeira espiga no colmo (Tabela 6). Enquanto o tratamento em que foi aplicado o esterco misto obteve menores valores médios em torno de 6,00 cm. De acordo com Miranda et al., (2003), a altura de planta extrema, a alta proporção entre altura de plantas e altura de espigas podem fazer com que a cultivar apresente maior suscetibilidade ao acamamento. Em estudo com avaliação de características agronômicas, Paziani et al. (2009) observaram que a altura de planta e de espigas foi o que mais obteve correlação com produção de massa verde, massa seca, grãos e matéria seca.

O número de espigas (NE) (Tabela 6) foi influenciado pelos tratamentos com adubação orgânica aplicados. A análise de variância pelo teste $\mathrm{F}$ indicou que os efeitos dos tratamentos com adubação orgânica no milho apresentaram diferença com significância em nível de 5\% $(\mathrm{P}<0,05)$. O tratamento com esterco caprino apresentou melhor desempenho diante os valores $(17,00)$, ao tempo que o esterco bovino apresentou valores médios de 5,25.

Tabela 6 - Comparação de médias de altura da primeira espiga (APE), número de espigas (NE) em função de diferentes fontes de adubação orgânica. Guanambi, BA, 2017 - 2018

\begin{tabular}{ccc}
\hline Tratamentos & APE $(\mathbf{c m})$ & NE \\
\hline Testemunha & $5,9 \mathrm{~A}$ & $8,5 \mathrm{BC}$ \\
Esterco Caprino & $7,1 \mathrm{C}$ & $17,0 \mathrm{~A}$ \\
Esterco Bovino & $13,9 \mathrm{AB}$ & $5,2 \mathrm{C}$ \\
Esterco Aviário & $9,6 \mathrm{BC}$ & $9,0 \mathrm{BC}$ \\
Esterco Misto & $6,0 \mathrm{C}$ & $12,7 \mathrm{AB}$ \\
\hline Média & $\mathbf{1 0 , 5}$ & $\mathbf{1 0 , 4 8}$ \\
\hline
\end{tabular}

Letras diferentes na coluna diferem entre si pelo teste de Kruskal - Wallis a 5\% de significância.

A produção média do milho com uso dos tratamentos se diferenciou estatisticamente. Para peso de espiga, os valores variaram entre $5,0 \mathrm{~kg}$ /vaso e 18,4 $\mathrm{kg} /$ vaso por espiga para os tratamentos com adubação orgânica.
Os tratamentos com esterco caprino e esterco misto foram os que mais incrementaram na variável peso médio da espiga/vaso, estes apresentaram valores médios de 18,4 kg/vaso e 16,6 kg/vaso, respectivamente. $\mathrm{O}$ esterco bovino propiciou menor valor médio, com 
uma produção de 5,0 kg/vaso. Para a produção do milho verde, é desejável obter uma porcentagem de espigas comerciais e peso de espigas comerciais elevados, uma vez que a comercialização também é feita com base nesses atributos.

Tabela 7 - Médias da produção do milho (peso da espiga/vaso em kg) em função de diferentes fontes de adubação orgânica. Guanambi, BA, 2017 - 2018

\begin{tabular}{cc}
\hline Tratamentos & Peso da espiga/vaso (kg) \\
\hline Testemunha & $11,3 \mathrm{AB}$ \\
Esterco Caprino & $18,4 \mathrm{~A}$ \\
Esterco Bovino & $5,0 \mathrm{C}$ \\
Esterco Aviário & $13,2 \mathrm{AB}$ \\
Esterco Misto & $16,6 \mathrm{~A}$ \\
\hline Média & $\mathbf{1 2 , 9}$ \\
\hline
\end{tabular}

Letras maiúsculas diferentes na coluna diferem entre si pelo teste de Kruskal - Wallis a 5\% de significância.

Em face aos dados apresentados e nas condições em que foi conduzido o presente experimento, os resultados mostram que para as variáveis avaliadas, os menores valores foram apresentados com uso do esterco bovino.

Com efeito, para a fertilização da cultura de milho, os agricultores podem usar diferentes fontes de esterco provenientes da criação de bovinos, frangos, caprinos na propriedade e da mão-de-obra familiar, reduzindo os custos de produção e a utilização de adubos químicos, favorecendo a menor contaminação do meio ambiente. Este fator é de suma importância para a agricultura familiar, em função da falta de condições financeiras dos agricultores para aquisição de insumos agrícolas e melhoria dos rendimentos da cultura.

\section{Conclusão}

O uso do esterco caprino melhora substancialmente o diâmetro do colmo e assegura maior número de espigas. A fonte de adubação mista proporcionou tendência de aumentar o no número de folhas.

A variável peso da espiga/vaso foram alteradas com o uso do esterco caprino e misto. Os menores valores foram apresentados com a utilização do esterco bovino.

\section{Referências}

Araújo, P. M.; Nass, L. L. 2002. Caracterização e avaliação de populações de milho crioulo. Scientia Agricola, Piracicaba, 59: 589-593. Doi: http:// dx.doi.org/10.1590/S0103-90162002000300027.

Barroso, A. A. F.; Gomes, E. E.; Lima, A. E. O.L.; Palácio, H. A. Q.; Lima, C. A. L. 2011. Avaliação da qualidade da água para irrigação na região Centro Sul no Estado do Ceará. Revista Brasileira de Engenharia Agrícola e Ambiental, Campina Grande, 15:588593. Disponível em: http://www.scielo.br/scielo.php?script=sci arttext\&pid $=\mathrm{S} 141543662011000600008 \& \operatorname{lng}=\mathrm{en} \& \mathrm{nrm}=\mathrm{isoDoi}$ : http://dx.doi.org/10.1590/S1415-43662011000600008

Carpentieri-Pípolo, V.; Souza, A. de,; Silva, D. A. da,; Barreto, T.P; Garbuglio, D.D.; Ferreira, J.M. 2010. Avaliação de cultivares de milho crioulo em sistema de baixo nível tecnológico. Acta Scientiarum Agronomy, Maringá, 32: 229-233. Doi: http://dx.doi.org/10.4025/ actasciagron.v32i2.430. Disponível em: http://periodicos.uem.br/ojs/ index.php/ActaSciAgron/article/view/430/430

Coimbra, R. R.; Miranda, G. V.; Cruz, S. D.; Melo, A. V. M.; Eckert, F. R. 2010. Caracterização e divergência genética de populações de milho resgatadas do Sudeste de Minas Gerais. Revista Ciência Agronômica, Fortaleza, 41: 159-166. Doi: http://dx.doi.org/10.5935/18066690.20100021. Disponível em: http://ccarevista.ufc.br/seer/index. $\mathrm{php} /$ ccarevista/article/view/347/420
Companhia Nacional de Abastecimento - CONAB. Acompanhamento da safra brasileira de grãos - Monitoramento agrícola - Cultivos de inverno (safra 2015) e de verão (safra 2015/16), Brasília, DF, 3:01-154, jan. 2016. Disponível em: https://www.conab. gov.br/info-agro/safras/graos/monitoramento-agricola/item/ download/13271_230de7f306720eca64005771374db84f

Cunha, F. L. 2013. Sementes da paixão e as políticas públicas de distribuição de sementes na Paraíba. Seropédica, RJ: Universidade Federal Rural do Rio de Janeiro, 184 f. Dissertação (mestrado). Disponível em: http://aspta.org.br/files/2013/10/Dissertacao-MestradoFlaviaLondres-vf.pdf

Durães, F. O. M.; Magalhaes, R. C.; Costa, J. D.; Fancelli, A. L. 1995. Fatores ecofisiológicos que afetam o comportamento do milho em semeadura tardia (safrinha) no Brasil central. Scientia Agrícola, Piracicaba, 52: 491-501. Doi: http://dx.doi.org/10.1590/S010390161995000300014. Disponível em: http://www.scielo.br/scielo. php?pid $=$ S0103-90161995000300014\&script $=$ sci_abstract $\&$ tlng $=$ pt

Eicholz, E. D.; Pereira, L. R. 2016. Produtividade de variedades de milho de polinização aberta no RS. Anais do Congresso Nacional de Milho e Sorgo: Milho e Sorgo as inovações mercados e segurança Alimentar, Bento Gonçalves, Brasil, 17. Disponível em: https://ainfo. cnptia.embrapa.br/digital/bitstream/item/149417/1/Eberson-1310.pdf 
Gomes, F. de S. et al.

Empresa Brasileira de Pesquisa Agropecuária - EMBRAPA. 2017. Manual de métodos de análise de solos. 3ed. Rio de Janeiro: Embrapa Solos. Disponível em: http://ainfo.cnptia.embrapa.br/digital/bitstream/ item/181717/1/Manual-de-Metodos-de-Analise-de-Solo-2017.pdf

Emygdio, B. M.; Silva, S. D. dos A. E.; Porto, M. P.; Teixeira, M. C. C.; Oliveira, A. C. B. De. 2008. Fenologia e características agronômicas de variedades de milho recomendadas para o RS. Pelotas: Embrapa Clima Temperado. Circular Técnica, 74: 234. Disponível em: https:// www.infoteca.cnptia.embrapa.br/infoteca/bitstream/doc/746790/1/ Circular74.pdf

Ferreira, A. O.; Sá, J. C. M.; Nascimento, C. G.; Briedis, C.; Ramos, F. S. 2010. Impacto de resíduos orgânicos de abatedouro de aves e suínos na produtividade do feijão na região dos campos gerais - PR - Brasil. Revista Verde de Agroecologia e Desenvolvimento Sustentável, 5: 15-21. Disponível em: https://www.gvaa.com.br/revista/index.php/RVADS/ article/view/340/398

Ferreira, C. F. 2009. Diagnose nutricional de diferentes cultivares de milho (Zea mays L.) de diferentes níveis tecnológicos. Curitiba: Universidade Federal Paraná, 114p. Dissertação, Mestrado em Ciências do Solo. Disponível em: http://www.pgcisolo.agrarias.ufpr. br/dissertacao/2009_02_27_ferrerira.pdf

Ferreira, D. F. 2011. Sisvar: um sistema computacional de análise estatística. Revista Ciência e Agrotecnologia, 35: 1039-1042. Doi: http://dx.doi.org/10.1590/S1413-70542011000600001.

Macêdo, R. B.; S. D. dos A. E.; Porto, M. P.; Teixeira, M. C. C. 2016. Cultura do Milho sob Manejo Orgânico e Tratamentos Alternativos de Sementes. Cadernos de Agroecologia, 11: 23-29, dez. Disponível em: http://revistas.aba-agroecologia.org.br/index.php/cad/article/ view/21294.

Milane, L. V.; Coradi, P. C.; Camilo, L. J.; Andrade, M. G. O. 2015. Alterações na qualidade física em grãos de milho durante armazenamento em ambiente natural e refrigerado. Anais do Congresso Brasileiro de Engenharia Agrícola - CONBEA, São Pedro-SP, 14. Disponível em: https://www.researchgate.net/publication/330971062_alteracoes na_qualidade_fisica_em_graos_de_milho_durante_armazenamento_ em_ambiente_natural_e_refrigerado.
Miranda, G. V.; Souza, L. V.; Fidelis, R. R.; Godoy, C. L.; Coimbra, R. R.; Melo, A. V. de; Guimarães, L. J. M. 2003. Potencial de melhoramento e divergência genética de cultivares de milho-pipoca. Pesquisa Agropecuária Brasileira, Brasília, 38: 681-688. Doi: http://dx.doi. org/10.1590/S0100-204X2003000600003.

Paziani, S. F.; Duarte, A.P.; Nussio, L.G.; Gallo, P.B.; Bittar, C.M.M.; Zopollatto, M.; Reco, P.C. 2009. Características agronômicas e bromatológicas de híbridos de milho para produção de silagem. Revista Brasileira de Zootecnia, 38: 411-417. Doi: http://dx.doi.org/10.1590/ S1516-35982009000300002.

Rodrigues, T. R. D.; Broetto, L.; Oliveira, P. S. R.; Rubio, F. 2012. Desenvolvimento da cultura do milho submetida a fertilizantes orgânicos e minerais. Bioscience Journal, Uberlândia, 28: 509-514. Disponível em: http://www.seer.ufu.br/index.php/biosciencejournal/article/ view/13243

Sampaio, E. V. S. B.; Resende, O.; Marçal, K. A. F.; Oliveira, D. E. C.; Simon, G. A. 2007. Eficiência da adubação orgânica com esterco bovino e com Egeria densa. Revista Brasileira Ciência do Solo, Viçosa, 31: 9951002. Doi: http://dx.doi.org/10.1590/S0100-06832007000500016.

Santos, M. da S.; Barros, M. K. L. V.; Barros, H. M. M.; Barosi, K. X.; Chicó, L. R. 2017. Sementes crioulas: Sustentabilidade no semiárido paraibano. Revista Agrarian Academy, Centro Científico Conhecer - Goiânia, 4: 403. Doi: http://dx.doi.org/10.18677/Agrarian_Academy_2017a39

Silveira, D. C.; Monteiro, V. B.; Tragnago, J. L.; Bonetti, L. P. 2015. Caracterização agromofologica de variedades de milho crioulo (Zea mays L.) na região noroeste do Rio Grande do Sul. Revista Ciência e Tecnologia, Rio Grande do Sul, 1: 01-11. Disponível em: http:// revistaeletronica.unicruz.edu.br/index.php/cienciaetecnologia/article/ view/592

Vieira, M. A. Camargo, M. K.; Daros, E.; Zagonel, J.; Koehler, H. S. 2010. Cultivares de milho e população de plantas que afetam a produtividade de espigas verdes. Acta Scientiarum Agronomy, 32: 81-86. Doi: http:// dx.doi.org/10.4025/actasciagron.v32i1.987 